\title{
AS PERSPECTIVAS DA CULTURA E EXTENSÃO NO CURSO DE ENFERMAGEM DA UNIVERSIDADE FEDERAL DA BAHIA
}

\author{
Miriam Santos Paiva*
}

Valda Lucia Rocha de Novaes*

Este trabalho destaca a importância da Universidade manter a indissociabilidade entre suas atividades fins, pois, até o momento o que se observa é que esta indissociabilidade se apresenta de forma descompensada.

Faz uma breve análise retrospectiva das atividades extensionistas, relata os projetos atuais e a perspectiva da extensão na Escola de Enfermagem da Universidade Federal da Bahia (UFBA) e, chama atenção para o fato de que a extensão deve desenvolver-se através de um processo de articulação com o ensino e a pesquisa, entendendo que estas atividades são complementares e diferenciadas, porém nunca desiguais hierarquicamente.

UNITERMOS: extensão, atividades extensionistas.

\section{INTRODUÇÃO}

A presença da Universidade na sociedade exige que ela se caracterize por uma atitude vigilante e crítica e, ao mesmo tempo, atende as questões relevantes e emergentes dos problemas do cotidiano da realidade social, o que the obriga a assumir um compromisso de responsabilidade e parceria com a sociedade em que se insere.

*Professoras Adjuntas do Departamento de Enfermagem Comunitária da Escola de Enfermagem da Universidade Federal da Bahia. 
A Universidade Pública tem buscado cumprir o seu papel de manter a indissociabilidade de suas atividades fins: Ensino, Pesquisa e Extensão, previstas na Lei 5540/68 e em outros documentos do Ministério da Educação e Cultura (MEC), bem como nos documentos das Instituições de Ensino Superior. Entretanto, esta proclamada indissociabilidade se apresenta de forma descompensada. Em geral, as atividades de ensino na graduação predominam; ao ensino de pós-graduação e a pesquisa vêm conquistando o seu espaço, a partir do aumento do número de cursos e do incremento na produção do conhecimento, porém, lamentavelmente, as atividades de extensão ainda buscam o reconhecimento e a legitimidade acadêmica.

A Universidade Federal da Bahia (UFBA), embora coloque em seus documentos oficiais a extensão universitária como atividade fim. (Estatuto da UFBA, Título IV Capítulo III Artigos 85 a 87 e no Regimento Geral, Título $\vee$ artigos 112 a 117), mantém esta descompensação entre as atividades fins.

O real sentido de EXTENSÃO significa estender "algo a alguém", isto representado pelo repasse do conhecimento e da vivência do docente/profissional a outros elementos que compõem os segmentos da sociedade, seja o aluno ou demais membros da comunidade, pois o homem, como um ser histórico, encontra-se constantemente a procura de novos conhecimentos, que the possibilite construir ou refazer o seu saber e the abrir os caminhos para outros horizontes, promovendo também sua melhor adaptação no mundo em que vive.

Assim, as atividades de Extensão na UFBA são dos seguintes tipos: PRESTAÇÃO DE SERVIÇOS À COMUNIDADE, que envolve assessoria, consultoria, serviços ambulatoriais, serviços tecnológicos, serviços laboratoriais, serviços técnicos e especializados, entre outros e EVENTOS, que englobam as atividades de educação não formal continuada e de difusão científico-cultural, podendo ter o caráter eventual ou permanente.

\section{A ESCOLA DE ENFERMAGEM E A EXTENSÃO}

\section{1 - Uma breve retrospectiva}

Tradicionalmente, a Escola de Enfermagem da UFBA, desde sua criação, desenvolve atividades extensionistas tanto de prestação de serviços, quanto de eventos. Entretanto, a recessão por que passa o país, vem reduzindo substancialmente, os financiamentos, que outrora, eram conseguidos nas agências financiadoras nacionais ou internacionais e, conseqüentemente atinge também a universidade em seu orçamento, principalmente, porque embora o Meca reconheça a Extensão como atividade fim, a verba a ela destinada é sempre pequena, e não há uma política de criação de bolsas de extensão para estagiários. 
Podemos destacar, nas duas últimas décadas, os principais projetos integrados que foram desenvolvidos pela Escola de Enfermagem da universidade Federal da Bahia (EEUFBA) e que muito contribuíram para a formação profissional dos alunos de enfermagem, o desenvolvimento da comunidade onde foram implementados e para o crescimento profissional dos docentes envolvidos.

A - Programa Integrado de Saúde Rural de Cruz das Almas

Com o objetivo de criar um modelo de extensão a partir da integração dos recursos institucionais existentes, das lideranças comunitárias e do envolvimento dos estudantes de enfermagem e do pessoal de nível médio e elementar, foi implantado na cidade de Cruz das Almas no Recôncavo Baiano o "Programa Integrado de Saúde Rural" que tinha como princípios programáticos a hierarquização das ações, a regionalização das instituições e a racionalização de recursos na prestação da assistência integral aos grupos selecionados.

O programa previa como estratégias a participação da comunidade e a simplificação da assistência e desenvolvia os seguintes sub-projetos: assistência pré-natal, puericultura, pediatria, saúde do escolar, controle das doenças transmissíveis, saneamento ambiental, imunização, educação em serviço e treinamento de pessoal. Participaram a Prefeitura Municipal de Cruz das Almas, o Funrural, e Santa Casa de Misericórdia, o INAMPS, a Secretaria Estadual de Saúde e a Universidade e contou com o apoio financeiro da Fundação Rockfeller. Este programa desenvolveu-se de 1978 a 1981, quando então terminou o convênio com a agência financiadora, porém como havia sido previsto neste convênio, as instituições governamentais assumiram as atividades de saúde do município nas formas previstas pelo Programa, inclusive a contratação do pessoal que era pago pelo Projeto. Foram os seguintes os resultados obtidos pelo programa: 1. Racionalização de recursos humanos, materiais e financeiros através da integração das instituições de saúde; 2. Hierarquização das ações de saúde; 3. Participação ativa da comunidade; 4. Ampliação da cobertura de assistência à saúde; 5 . Melhoria do sistema de notificação de doenças e óbitos; 6. Capacitação de recursos humanos de nível superior, médio e elementar; 7. Criação da Diretoria Regional de Saúde, com a absorção do programa pela Secretaria de Saúde ${ }^{2}$.

B - Programa de Desenvolvimento Rural Integrado de Sapeaçu (PDRI)

Este programa desenvolveu-se no início da década de 80, na cidade de Sapeaçu, também no recôncavo Baiano e com apoio financeiro da fundação Rockfeller. O objetivo era de desenvolver um programa de Ação comunitária e envolveu a participação das Escolas da área da saúde, educação, ciências sociais e agronomia. A área da saúde estava representada pelas Escolas de Enfermagem, Nutrição, Medicina e Odontologia.

Os princípios adotados no programa de saúde eram o de simplificação da assistência, hierarquização das ações, participação comunitária, integração das instituições e capacitação de recursos humanos.

Os principais resultados foram o envolvimento da comunidade, contratação 
de pessoal capacitado pelo programa, modificações no currículo das escolas de $1^{\circ} \mathrm{grau}$, integração das atividades de saúde desenvolvidas pelas instituições locais, treinamento de professores e supervisores locais, assistência técnica aos agricultores, instalação de hortas comunitárias, censo demográfico; aumento da cobertura bucal, utilização da técnica de solo e cimento para as atividades de saneamento ambiental e avaliação do estado nutricional da população.

Este programa contava com uma enfermeira residindo no local para coordenar as atividades de saúde, permitiu ampla participação de alunos de graduação e pósgraduação, tanto em estágios curriculares, quanto extra curriculares das escolas participantes e também do curso de engenharia sanitária. As atividades encerraram-se no ano de 1983, quando ficou o convênio, porém aquelas relacionadas com a área de saúde foram englobadas pela Secretaria Municipal de Saúde ${ }^{8}$.

\section{C - Campus Avançado de Barreiras}

Ainda buscando desenvolver sua política de interiorização nas ações extensionistas, a Escola de Enfermagem participou do Campus Avançado de Barreiras, no Oeste do estado, e junto com as Escolas da Educação, Arquitetura, Agronomia e Serviço Social (UCSAL) passou a integrar o grupo tarefa universitária (G.T.U), desde as primeiras discussões para a assunção, pela UFBA, do Campus Avançado, em convênio com o Projeto Rondon, que durou até 1990.

Participaram das atividades alunos de graduação e pós-graduação, através de estágios curriculares e extra curriculares e foram desenvolvidos os seguintes subprogramas: - saúde do escolar, que obteve financiamento do MEC; - assistência à criança no Lar Batista e na Creche Municipal; - assistência de enfermagem à família; identificação e orientação de parteiras leigas; - desenvolvimento comunitário através do programa "saúde como fator de melhoria das condições de vida" financiado pela Companhia de Desenvolvimento e Ação Regional do Além São Francisco (CAR); - o programa educativo sobre saúde na Rádio Barreiras; - o programa de saneamento ambiental em convênio com a ex-Fundação Sesp e; - o programa de capacitação de professoras primárias para atenção à saúde ${ }^{1}$.

Outros projetos foram desenvolvidos pela Escola de Enfermagem tanto no interior, quanto na periferia de Salvador, como o programa de assistência à gestante de Pau da Lima, o de desenvolvimento comunitário de Alto das Pombas, o ambulatório de assistência a pacientes portadoras de hipertensão arterial no Hospital das Clinicas, entre outros, ligados a área de prestação de serviços. As atividades de educação não formal continuada e os eventos científicos culturais são muitos e tornariam longa e cansativa esta narrativa, mas também foram planejadas e executadas pela EE ao longo destes anos. 


\section{2 - Projetos atuais e a perspectiva da extensão na Escola de Enfermagem da UFBA}

A - O Projeto Cansanção é um programa Interdisciplinar de Integração Universitária que vem sendo desenvolvida há 08 (oito) anos em uma área rural do Semi-árido baiano, por professores e estudantes de graduação da Universidade Federal da Bahia. Tem como objetivo apoiar e estimular a população a se organizar politicamente, aprendendo a reivindicar para o atendimento de suas necessidades e conseqüentemente melhorar a qualidade de vida, isto com o apoio e o trabalho envolvendo diversas áreas: Agronomia e Veterinária no incentivo a produção agrícola e na melhoria de crias; Sociologia na estimulação e fortalecimento da mobilização; Arquitetura na construção de reservatórios domiciliares e comunitários para captação e armazenamento da água da chuva, melhoria da habitação e construção de prédios comunitários (casas de farinha, sede das associações e armazéns comunitários) e na área de saúde um trabalho voltado para práticas educativas com orientações que atendam as necessidades da população, identificação e tratamento de crianças desnutridas e com verminose, imunização, realização de cursos de primeiros socorros e atendimento odontológico preventivo e curativo. Estas ações surtiram efeitos significativos na melhoria da qualidade de vida da população, expressada pela diversificação da produção agrícola, inicio de um processo de mobilização e a melhoria no atendimento das necessidades de saúde, associada à aquisição de conhecimentos importantes para as ações preventivas.

B - ATENÇÃO À SAÚDE DO IDOSO: um programa que vem sendo desenvolvido em um Centro Social Urbano (CSU) na periferia da cidade de Salvador. É considerado o primeiro Ambulatório de Enfermagem específico do idoso, e visa, essencialmente, implantar ações gerais de saúde para idosos e familiares através de: consulta de enfermagem, encaminhamentos a outros profissionais da área de saúde e trabalho educativo com grupos de Diabéticos, Hipertensos e pré-idosos e atua ainda em saúde mental. As atividades deste programa são realizadas por 13 professoras da Escola de Enfermagem do Departamento de Enfermagem Médico Cirúrgica e Administração em Enfermagem, 02 (dois) enfermeiros da comunidade e alunos de graduação bolsistas, que atendem 03 (três) vezes por semana no Ambulatório do CSU.

C - APRENDENDO E ENSINANDO SOBRE AIDS: um programa educativo de prevenção da AIDS que atuará junto a grupos especiais de mulheres universitárias, alunos do $1^{\circ}$ e $2^{\circ}$ graus e trabalhadores das empresas da rede municipal. É um projeto financiado pelo Banco Mundial, em convenio da UFBA com a Prefeitura Municipal de Salvador. Este programa será desenvolvido com a participação dos grupos de estudo sobre a saúde da Mulher (GEM), de atenção à criança e adolescente (CRESCER) e o de Vigilância à Saúde, todos do Departamento de Enfermagem Comunitária. Este Projeto tem a finalidade de educar preventivamente sobre AIDS e de formar multiplicadores junto as populações especificas citadas, 
bem como produzir o material educativo (folders, cartilhas, cartazes, vídeos, etc.) especifico para cada grupo populacional.

D - PROJETO UNI - Este projeto encontra-se em fase de negociação com a Fundação Kellogg, que já desenvolve projetos desta natureza com outras Universidades.

O principio fundamental, utilizado em todos os projetos UNI desenvolvidos no país, é o de Integração Ensino Serviço, na perspectiva de articular universidade, Serviço e Comunidade.

Na UFBA, foi escolhido o Distrito Sanitário Docente Assistencial, Barra/Rio Vermelho e estão participando as Escolas de Enfermagem, Medicina, Nutrição, Farmácia e Odontologia.

O projeto prevê na área de ensino a adoção de propostas com metodologias inovadoras e de caráter interdisciplinar, podendo inclusive apontar mudanças curriculares.

Na perspectiva do Serviço será prestado o apoio necessário ao fortalecimento da estruturação do distrito Sanitário.

Quanto a comunidade o projeto desenvolverá suas atividades com a participação Comunitária e deve promover o desenvolvimento de lideranças.

Este projeto foi elaborado com a participação de representantes da Prefeitura de Salvador, das Escolas da UFBA que estão envolvidas, dos serviços existentes no distrito (gerente do distrito e outros profissionais) e da comunidade (pastoral da saúde e associações de moradores dos bairros pertencentes ao Distrito).

A coordenação de elaboração do projeto ficou a cargo da Escola de Enfermagem.

$\mathrm{E}$ - Ações de natureza educativa e assistencial dentre as quais destacamos aquelas relacionadas à educação continuada geralmente em atendimento a grupos ou instituições interessados na sua promoção, atuando como elemento de desenvolvimento sócioeconômico e cultural da comunidade na qual está envolvida. Tem acontecido com maior freqüência os ligados a Primeiros Socorros, Cólera, AIDS, Imunização, Reciclagem de profissional de nível médio, Higienização, Infecção Hospitalar, Metodologia Científica e práticas educativas em Saúde da Mulher.

Uma prática constante da nossa Escola tem sido também a participação dos professores em assessorias a diversas instituições públicas do Estado e município, que, apesar de não serem consideradas uma atividade extensionista, é uma característica dos nossos docentes.

No Campo da difusão científica e cultural a UFBA dispõe de alguns mecanismos que facilitam esta atividade, embora esteja necessitando de maior incremento.

Até a presente data, a UFBA não conseguiu publicar um catalogo anual das atividades extensionistas, o que vem dificultando a divulgação destas atividades. Desta forma, a divulgação acaba sendo de responsabilidade dos departamentos, ou dos professores que utilizam os meios de comunicação da mídia na ocasião das 
realizações dos eventos; os congressos, seminários e outros; ou se o projeto de extensão prevê a realização de pesquisa, é possível divulgá-lo no Catálogo de Produção Científica, artística e literária, publicado pela Pró Reitoria de Pós-Graduação e Pesquisa.

A UFBA dispõe ainda, do Centro editorial que recentemente foi transformado em editora, e de uma gráfica que juntos possibilitam a publicação da Revista UNIVERSITAS (UFBA), de revistas de algumas Escolas, como, por exemplo, de Enfermagem - REVISTA BAIANA DE ENFERMAGEM - e de publicações independentes, como livros escritos por docentes, programas realizados pela UFBA (Projeto Cansanção), entre outros.

\section{CONSIDERAÇÕES FINAIS}

As atividades de extensão permitem aos docentes e aos discentes o convívio direto com situações e problemas que emergem do próprio Contexto Sócio Cultural no qual a UNIVERSIDADE se insere. Por esta razão, se faz necessário, que todos os esforços sejam envidados, para que não haja uma descompensação entre as atividades fins da Universidade.

A extensão deve desenvolver-se, através de um processo de articulação com o ensino e a pesquisa, entendendo que estas atividades são complementares e diferenciadas, porém nunca desiguais hierarquicamente.

Para tanto, o MEC e as Universidades precisam estabelecer uma política democrática para as atividades de extensão, bem como institucionalizá-la.

A UFBA, num Seminário de Extensão ocorrido recentemente, destacou alguns pressupostos essenciais para a institucionalização das atividades de extensão ${ }^{5}$, com os quais concordamos e por esta razão apresentaremos a seguir:

01. Valorização da atividade de extensão como parcela legitima da carga horária docente/departamento.

02. Responsabilização dos Departamentos, dos Conselhos Departamentais e Órgãos Suplementares como instancia legitima e autônoma na definição de sua política e das atividades de extensão.

03. Definição da Pró Reitoria como Órgão de centralização e divulgação das atividades de extensão desenvolvidas na UFBA, cabendo a esta manter um banco atualizado de informações e um cadastro atualizado de possíveis fontes de financiamento e, gerir um fundo universitário de extensão, entre outras atividades.

04. Compreensão da Câmara de Extensão como espaço normativo, legislador, de articulação de atividades de extensão interunidades e de formulação da política de extensão para a UFBA.

05. Delineamento do conselho de Coordenação e da Reitoria como lugares 
complementares de elaboração e concretização de uma política universitária de extensão.

06. Estudo e viabilização de medidas que transformem a extensão em atividade a ser realizada pelo estudante, como momento significativo de seu exercício discente de aprendizado.

Esperamos que com a deflagração do processo de Estatuinte na UFBA, estas medidas possam, realmente, serem implantadas, permitindo, enfim, uma precisa aproximação da universidade com a comunidade.

\section{PERSPECTIVES OF CULTURE AND EXTENSION IN THE NURSING COURSE OF THE FEDERAL UNIVERSITY OF BAHIA}

The present article emphasizes the importance of the University to maintain the indisociability among its finality activities whereas, at the moment, this indisociability shows up in a non compensated form.

It comprehends a brief retrospective analysis of the extension activities, reporting the actual projects and the extension perspective at the College of Nursing, Federal University of Bahia, directing the attention to the fact that extension ought to be developed through a process of articulation with teaching and research, as these activities are complementaries and different, but never unequal hierarchically.

UNITERMS: extension, extension activities.

\section{LAS PERSPECTIVAS DE LA CULTURA Y EXTENSIÓN EN EL CURSO DE ENFERMERÍA DE LA UNIVERSIDAD FEDERAL DE LA BAHIA}

Este trabajo destaca la importancia de la Universidad mantener la unidad entre sus actividades de objetivo oues, hasta el momento, lo que se observa es que esta unidad se presenta de forma descompensada.

Hace un breve análisis retrospectiva de las actividades extensionista, relata los proyectos actuales y la perspectiva de la extensión en la Escuela de Enfermería de la 
Universidad Federal de la Bahia y, llama la atención para el hecho de que la extensión debe desarrollarse a través de un proceso de articulación con la enseñanza y la investigación, entendiendo que estas actividades son complementarias y diferenciadas, pero nunca desiguales jerárquicamente.

UNITERMOS: extensión, actividades extensionistas.

\section{REFERÊNCIAS BIBLIOGRÁFICAS}

01. ALMEIDA, M. M. G. de, FARIAS, F. C. Enfermagem no Campus Avançado de Barreiras. Relato de experiência. Rev. Baiana Enfermagem, v. 1, n. 2, p. 70-83, dez. 1985.

02. ALMEIDA, M. M. G. de et al. Avaliação de um programa de Saúde Rural: Cruz das Almas - Ba. Rev. Baiana Enfermagem, v. 1, p. 57-72, 1981 (número especial).

03. FREIRE, P. Extensão ou comunicação? Trad. de Rosisca Darcy de Oliveira. 3 ed. Rio de Janeiro: Paz e Terra, 1977. p. 93 (Coleção O Mundo Hoje, v. 24).

04. MAGNAVITA, P. R. Concepção e diretrizes de extensão. In: SEMINÁRIO DE EXTENSÃO DA UFBA. 1., Salvador, 1992. p. 14 (mimeografado) (Texto preliminar para o grupo de trabalho A). p. 14 (mimeografado).

05. RUBIM, A. A. C., BIÃO, A. J., MOURA, P. Papel, relações e funcionamento das instâncias institucionais da UFBA na atividade. In: SEMINÁRIO DE EXTENSÃO DA UFBA. 1., Salvador, 1992. p. 3 (mimeografado) (Texto preliminar para grupo de trabalho C). p. 3 (mimeografado).

06. SEMINÁRIO DE EXTENSÃO DA UFBA. 1., 1992, Salvador. Documento Final.... Salvador: Câmara de Extensão, UFBA, 1992. 2 Of. (mimeografado).

07. SEMINÁRIO DE INTEGRAÇÃO DAS ATIVIDADES DE ENSINO PESQUISA E EXTENSÃO. 1., 1992, Salvador. Relatório.... Salvador: Escola de Enfermagem, UFBA, 1992. 6 f. (mimeografado).

08. SOUZA, I. M. de M., NOVAES, V. L. R. de. Programa de desenvolvimento rural integrado de Sapeaçu: sub-programa de enfermagem. Salvador, 1983, p. 12 (mimeografado).

09. UNIVERSIDADE FEDERAL DA BAHIA. Projeto cansanção: uma vivência da universidade no sertão da Bahia. Salvador: Coordenação Central de Extensão, UFBA. 1992. p 95.

10. Escola de Enfermagem. Departamento de Enfermagem Comunitária. Programa Integrado de Saúde Rural - Cruz das Almas. 

Salvador: Assessoria de Planejamento, UFBA. 1988. v. 2. Salvador, 1976. p. 63 (mimeografado).

12. Resolução $n^{\circ}$ 001, 29 de abril de 1993. Dispõe sobre as atividades de extensão, revogando as normas vigentes e dá novas providências. Salvador: Universidade Federal da Bahia - Conselho de Coordenação, 19-93. 3 f. (mimeografado). 